\title{
Assessment of simulated mandibular condyle bone lesions by cone beam computed tomography
}

\section{Alexandre Perez Marques ${ }^{(a)}$ Andréia Perrella ${ }^{(a)}$ \\ Emiko Saito Arita ${ }^{(a)}$ Marlene Fenyo Soeiro de Matos Pereira $^{(a)}$ \\ Marcelo de Gusmão Paraíso Cavalcanti ${ }^{(a)}$}

(a) Departamento de Estomatologia, Faculdade de Odontologia, Universidade de São Paulo, São Paulo, SP, Brasil.
Corresponding author: Alexandre Perez Marques

Rua Vice-governador Rubens Berardo, 175,

Bloco 1, apt. 904 - Gávea

Rio de Janeiro - RJ - Brazil

CEP: 22451-070

E-mail: alexperez34@gmail.com

Received for publication on May 12, 2010 Accepted for publication on Sep 10, 2010

\begin{abstract}
There are many limitations to image acquisition, using conventional radiography, of the temporomandibular joint (TMJ) region. The Computed Tomography (CT) scan is a better option, due to its higher accuracy, for purposes of diagnosis, surgical planning and treatment of bone injuries. The aim of the present study was to analyze two protocols of cone beam computed tomography for the evaluation of simulated mandibular condyle bone lesions. Spherical lesions were simulated in 30 dry mandibular condyles, using dentist drills and drill bits sizes 1, 3 and 6. Each of the mandibular condyles was submitted to cone beam computed tomography (CBCT) using two protocols: 1) axial, coronal and sagittal multiplanar reconstruction (MPR); and 2) sagittal plus coronal slices throughout the longitudinal axis of the mandibular condyles. For these protocols, 2 observers analyzed the CBCT images independently, regarding the presence or not of injuries. Only one of the observers, however, performed on 2 different occasions. The results were compared to the gold standard, evaluating the percentage of agreement, degree of accuracy of CBCT protocols and observers' examination. The $\mathrm{z}$ test was used for the statistical analysis. The results showed there were no statistically significant differences between the 2 protocols. There was greater difficulty in the assessment of small-size simulated lesions (drill \# 1). From the results of this study, it can be concluded that CBCT is an accurate tool for analyzing mandibular condyle bone lesions, with the MPR protocol showing slightly better results than the sagittal plus coronal slices throughout the longitudinal axis.
\end{abstract}

Descriptors: Cone-Beam Computed Tomography; Protocols; Bone Diseases; Temporomandibular Joint.

\section{Introduction}

Many injuries, inflammatory and degenerative diseases, postural disorders, traumas and other abnormalities compromise the equilibrium of temporomandibular joint components, resulting in its disorder or dysfunction. ${ }^{1}$ Complementary radiographic exam is an important instrument to diagnose and evaluate the degree of such anomalies, which affect the temporomandibular joint. Radiographic evidence that characterizes the presence of degenerative disease in the joints includes erosions of the cortical boundary and reduction of the joint biological space. ${ }^{2}$

Computed tomography $(\mathrm{CT})$ is an exam that is indicated because it 
presents high specificity and sensitivity, essential to the diagnosis, planning and treatment of TMJ bone lesions. ${ }^{3}$ Using CT, it is possible to analyze the boundary of the mandibular condyle, its position in the mandibular fossa and the involvement of the cortical bone in relation to the bone lesions. ${ }^{4,5} \mathrm{Sev}-$ eral bone alterations that occur in the TMJ, such as erosions and osteophytes in the mandibular condyle, are difficult to detect using conventional radiography and thus necessitate the use of CT. ${ }^{6}$

$\mathrm{CT}$ has been used to diagnose several bone abnormalities of the TMJ, from osteophytes to tumors. ${ }^{6-8}$ According to Marques and Moraes, ${ }^{9}$ erosion in the mandibular condyle is prevalent in $7.9 \%$ of total TMJ alterations.

Cone beam computed tomography (CBCT) was introduced during the last decade. It uses X-ray exposure in cone shapes instead of slices, as in the spiral CT, for image acquisition. This technology presents less X-ray exposure and lower cost to the patient than the spiral CT, in addition to its capacity to capture images in just one rotation of the X-ray source..$^{10,11}$

This study aims to demonstrate the sensitivity and specificity of cone beam computed tomography, and to establish a more adequate protocol for the post-processing of images for the interpretation of simulated mandibular condyle bone lesions.

\section{Material and Methods}

The present study was submitted to and approved by the Committee of Ethics in Research of the School of Dentistry, University of São Paulo, under protocol \# 26/2009. A total of 15 macerated human mandibles (with 30 mandibular condyles) were used in this study. Anatomical specimens of adult mandibles whose mandibular condyles presented bilaterally a satisfactory aspect of preservation were selected. Each mandibular condyle was divided into five regions: anterior, lateral, posterior, medial and superior, totaling five specific areas. Using a $\mathrm{KaVo}^{\circledR}$ high-speed handpiece (KaVo do Brasil, Joinville, SC, Brazil) and three surgical carbide ball drill bits for dental use, with different head diameters $(\# 1,3,6)$, trademark Jet-Carbide Burs ${ }^{\circledR}$ (Carbide Burs, Morrow, $\mathrm{OH}, \mathrm{USA}$ ), holes were made randomly in one or more portions of each mandibular condyle, that either did or did not reach the cortical and the medullar bone, to simulate bone lesions. After drilling the holes, all the mandibles were submitted to cone beam computed tomography.

In order to simulate the X-ray attenuation caused by soft tissues in vivo, the mandibles were inserted one by one into a plastic container with water until they were completely submersed.

The acquisition of images by CBCT was accomplished using the i-CAT Classic ${ }^{\circledR}$ system (Imaging Sciences International, Hatfield, PA, USA) (Figure 1). First, the initial scan was performed with the slicing plane in axial orientation, and leveled with the mandible base up to the region of the mandibular condyle. These images were obtained using the following CBCT acquisition protocol:

- Voxel thickness: $0.25 \mathrm{~mm}$

- Thickness of the sagittal and coronal slice along the longitudinal axis of the mandibular condyle: $1 \mathrm{~mm}$

- Spacing between slices: $1 \mathrm{~mm}$

- Acquisition volume: mandible

- Time: 40 seconds

- Parameters: $90 \mathrm{kVp}$ and $7 \mathrm{~mA}$

- Field of view (FOV): $13 \mathrm{~cm}$

All the original images from the CBCT were saved on CD-ROM, to be evaluated later at an independent Dell Precision $390^{\circledR}$ workstation (Dell Inc., Round Rock, Texas, USA), with a 20" flat screen monitor - Windows $\mathrm{XP}^{\circledR}$ (Microsoft, Redmond, WA, USA), and the files were also saved together using the i-CAT Vision ${ }^{\circledR}$ software (Imaging Sciences International, Hatfield, PA, USA).

The single criterion for the analysis of lesions in the tomographic images versus the gold standard was verification of the presence or absence of the lesion (hole) in the mandibular condyle.

In relation to the standardization of the analyses, the observers interpreted the tomographic images of the mandibular condyles in the following way:

- Protocol 1 - Multiplanar reconstructions (MPR) - axial, coronal and sagittal - from the CBCT, with 1-mm slice thickness and 1-mm spacing, were interpreted at the independent workstation using the i-CAT Vision ${ }^{\circledR}$ software (Figure 2). 


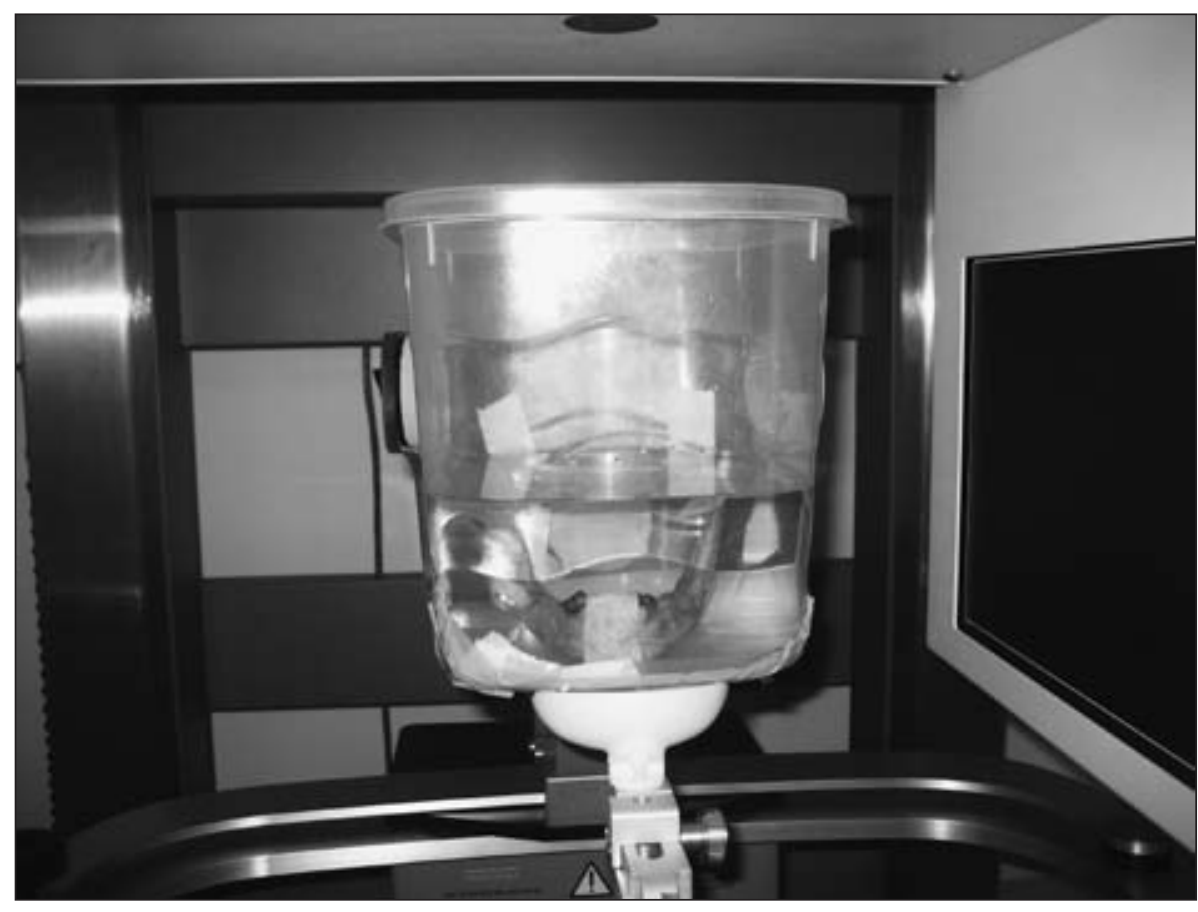

Figure 1 - Container with water and the mandible simulating patient position in the i-Cat Vision ${ }^{\circledR}$ device for CBCT acquisition.

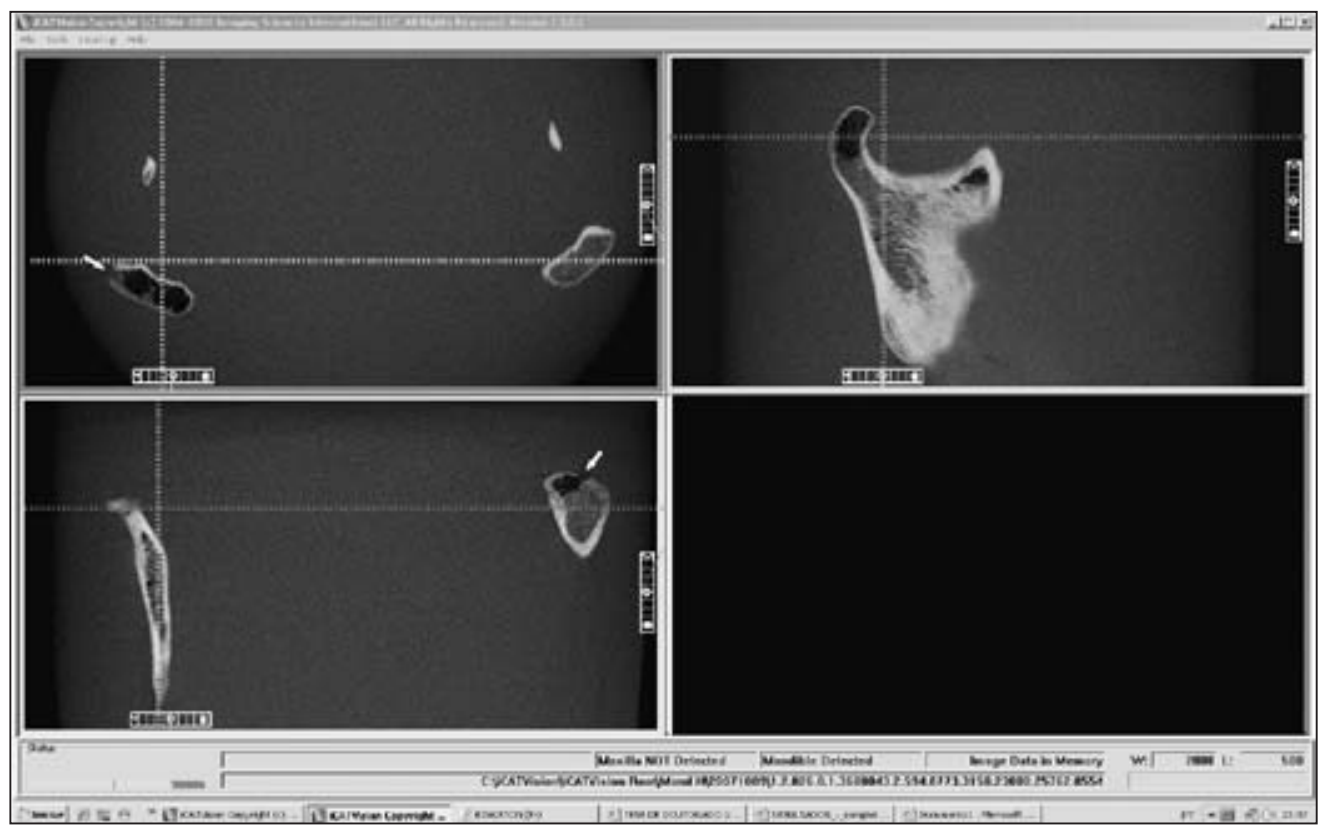

Figure 2 - Multiplanar reconstructions (axial, coronal and sagittal) of the mandibular condyle originated from CBCT by i-Cat Vision ${ }^{\circledR}$.

- Protocol 2 - Sagittal and coronal slices along the longitudinal axis of the mandibular condyle from the CBCT, with 1-mm slice thickness and 1-mm spacing, were also observed at the same independent workstation using the same i-CAT Vision ${ }^{\circledR}$ software (Figures 3 and 4).

The systematic evaluation of the tomographic images was performed by two observers, individually, following the principle of randomization of the images for each observer. Both observers (PhD students) were calibrated by means of images acquired for this research, in a random form, concerning the agreement of the hypodense images in the different regions of the mandibular condyles, on two 
Figure 3 - Axial slice of the mandibular condyle showing the longitudinal axis of the mandibular condyles and sagittal slices in the medial-lateral direction (i-CAT Vision ${ }^{\circledR}$ ) showing the hypodense images in the mandibular condyle (arrows).

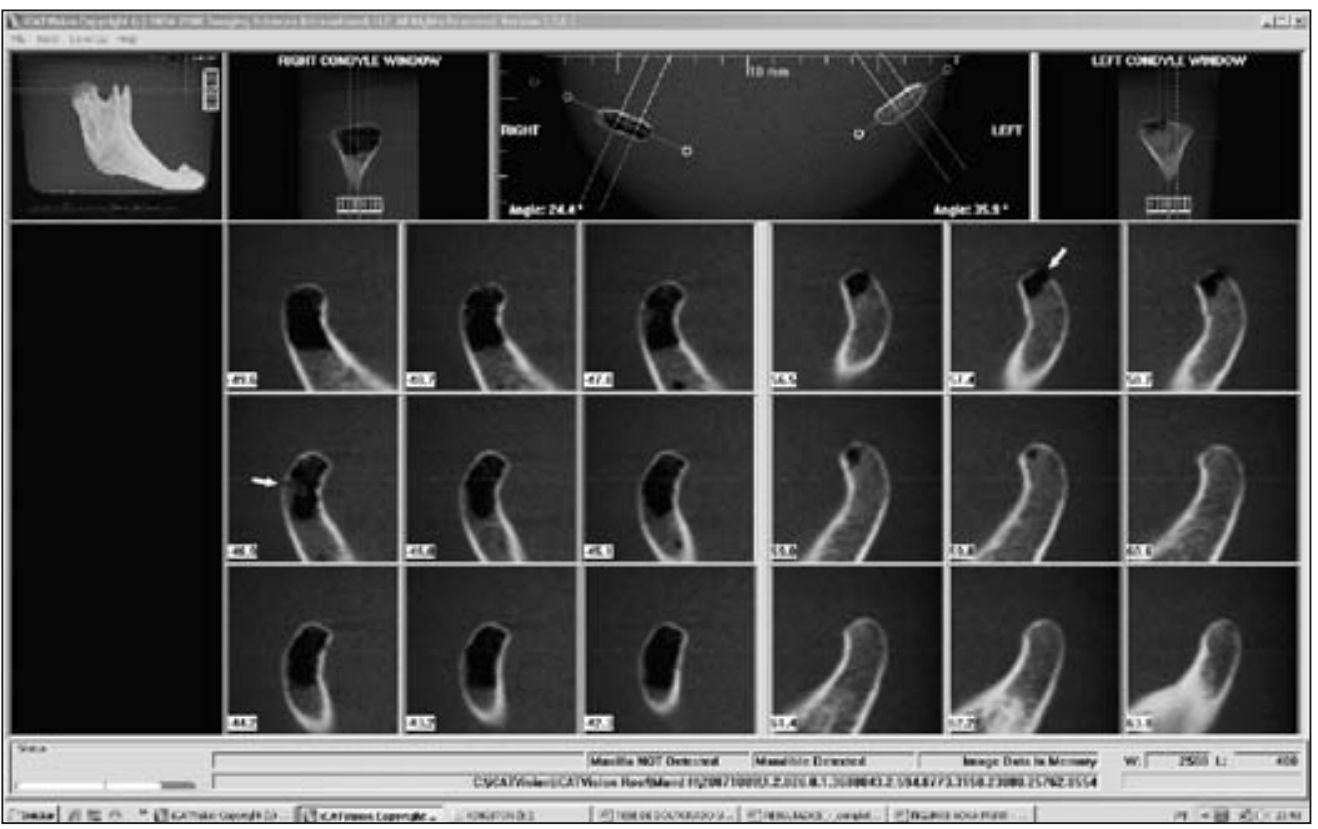

Figure 4 - Axial slice of the mandibular condyle showing the transversal axis of the mandibular condyles and coronal slices in the anteroposterior direction (i-CAT

Vision ${ }^{\circledR}$ ) showing the

hypodense images in the mandibular condyles (arrows).

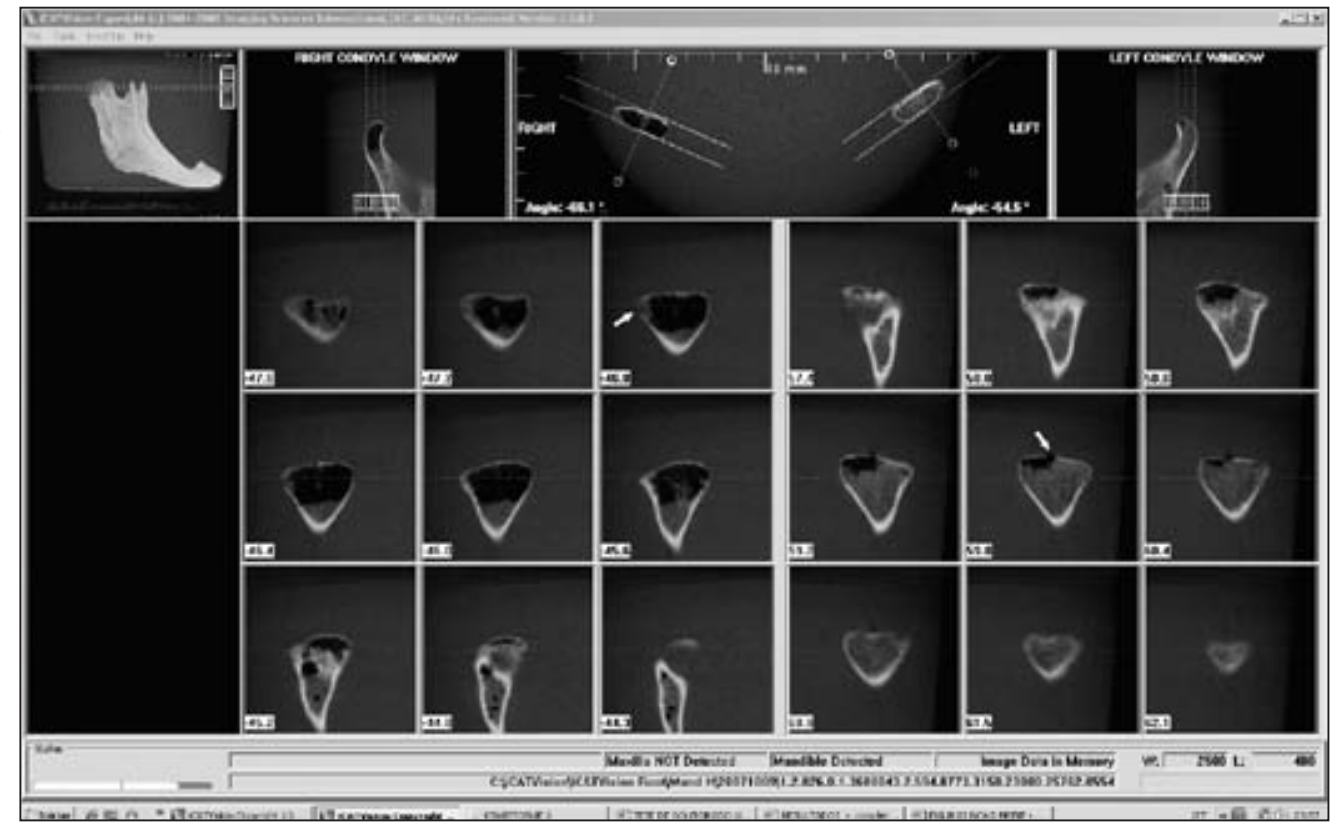

different occasions at an interval of one week. The analyses were performed in the following manner: observer 1 analyzed the images at two distinct times (with an interval of seven days), labeled as observer 1 (first analysis) and observer 1' (second analysis). The other observer (observer 2), independently, analyzed the images only once. The second analysis of observer 2 was not carried out because it would not have increased sufficiently the number of observers to a statistically representative sample, and it would have increased costs and time without contributing to the accuracy of the results.

For the analysis of the lesions shown in the CBCT versus the gold standard, the presence or absence of bone lesions (holes) and their locations in all mandibular condyles were evaluated in each protocol of analysis.

For the statistical analysis of this research, the 
percentages of the agreements of each observer were calculated in relation to the gold standard.

For the statistical treatment of the data in this study, the $\mathrm{z}$ test was used with a level of significance of $5 \%$. Statistically significant differences were observed when the resultant value of $\mathrm{P}$ in the test was less than or equal to $5 \%$.

The information from observer 1 was used to calculate the sensitivity and the specificity of the protocols of CBCT.

\section{Results}

Tables 1 through 6 present the information from the observers in relation to the presence or absence of holes (lesions), and also from the analyses of the two CBCT protocols for assessing simulated bone lesions. The tables also show intra-observer and inter-observer comparisons using the $\mathrm{z}$ test, and results of sensitivity and specificity, aiming at the validation of the methods.

In the statistical analysis, the data recorded by the observers were compared to the gold standard (data shown in Table 1), using the $\mathrm{z}$ test.

Table 2 presents the average percentage of agreements, in relation to the gold standard, for the as- sessment of the protocols used, independent of the absence of a hole or the size of the drill bit used to create the hole.

Table 3 presents the $\mathrm{z}$ test results for the intraand inter-observer comparisons, for each protocol used.

As no statistically significant differences were found in the intra-observer percentages of agreements, and one protocol showed significant difference in the inter-observers percentages of agreements, the information coming from observer 1 was used to calculate the sensitivity and the specificity of the protocols utilized, as well as to make the comparisons of the percentages of agreements between

Table 1 - Gold standard. Number of holes made in the mandibular condyle, by region.

\begin{tabular}{c|c|c|c|c|c}
\hline \multirow{2}{*}{$\begin{array}{c}\text { Size of } \\
\text { simulated } \\
\text { lesion }\end{array}$} & \multicolumn{5}{|c}{ Number of lesions made, by region } \\
\cline { 2 - 6 } & Anterior & Lateral & Posterior & Medial & Superior \\
\hline Absent & 9 & 8 & 7 & 5 & 7 \\
\hline Drill bit 1 & 7 & 8 & 6 & 10 & 7 \\
\hline Drill bit 3 & 7 & 7 & 9 & 7 & 8 \\
\hline Drill bit 6 & 7 & 7 & 8 & 8 & 8 \\
\hline
\end{tabular}

\begin{tabular}{|c|c|c|c|c|}
\hline \multirow{4}{*}{$\begin{array}{r}\text { Table } 2 \text { - Average } \\
\text { comparison of } \\
\text { agreements, in relation to } \\
\text { the gold standard, taking } \\
\text { into consideration all } \\
\text { regions of the mandibular } \\
\text { condyles observed. }\end{array}$} & Protocol & \multicolumn{3}{|c|}{$\begin{array}{l}\text { Average comparison of agreements, in relation to } \\
\text { the gold standard, taking into consideration all regions } \\
\text { of the mandibular condyles observed }\end{array}$} \\
\hline & & Observer 1 & Observer $1^{\prime}$ & Observer 2 \\
\hline & $\begin{array}{c}\text { CBCT } \\
\text { i-CAT Vision }{ }^{\circledR} \\
\text { Multiplanar reconstruction }\end{array}$ & 0.72 & 0.70 & 0.90 \\
\hline & $\begin{array}{c}\text { CBCT } \\
\text { i-CAT Vision }{ }^{\circledR} \\
\text { Sagittal/coronal slices }\end{array}$ & 0.70 & 0.78 & 0.93 \\
\hline
\end{tabular}

Table 3 - Intra- and interobserver comparisons, utilizing the $z$ test, for each protocol used.

\begin{tabular}{c|c|c}
\hline \multirow{2}{*}{ Protocol } & \multicolumn{2}{|c}{ P values and statistical interpretations associated with the z test } \\
\cline { 2 - 3 } & Obs. 1 vs. Obs. 1' & Obs. 1 vs. Obs. 2 \\
\hline CBCT & $\mathrm{P}=0.909$ & $\mathrm{P}=0.148$ \\
i-CAT Vision ${ }^{\circledR}$ & No difference & No difference \\
Multiplanar reconstruction & intra-observer & inter-observers \\
\hline CBCT & $\mathrm{P}=0.680$ & $\mathrm{P}=0.05^{*}$ \\
i-CAT Vision ${ }^{\circledR}$ & No difference & Difference exists \\
Sagittal/coronal slices & intra-observer & inter-observers \\
\hline
\end{tabular}

*Statistically significant difference for $\mathrm{P} \leq 0.05$. 
Table 4 - Sensitivity of the protocols utilized for each region examined by observer 1 .

\begin{tabular}{c|c|c|c|c|c}
\hline \multirow{2}{*}{ Protocol } & \multicolumn{4}{|c}{ Sensitivity } \\
\cline { 2 - 6 } $\begin{array}{c}\text { CBCT } \\
\text { i-CAT Vision }\end{array}$ & Anterior & Lateral & Posterior & Medial & Superior \\
\hline $\begin{array}{c}\text { Multiplanar reconstruction } \\
\text { CBCT }\end{array}$ & 0.47 & 0.81 & 0.91 & 0.60 & 0.69 \\
\hline $\begin{array}{c}\text { i-CAT Vision } \\
\text { Sagittal/coronal slices }\end{array}$ & 0.42 & 0.54 & 0.82 & 0.56 & 0.78 \\
\hline
\end{tabular}

Table 5 - Specificity of the protocols utilized for each region examined by observer 1 .

\begin{tabular}{c|c|c|c|c|c}
\hline \multirow{2}{*}{ Protocols } & \multicolumn{5}{|c}{ Specificity } \\
\cline { 2 - 6 } & Anterior & Lateral & Posterior & Medial & Superior \\
\hline $\begin{array}{c}\text { CBCT } \\
\text { i-CAT Vision }\end{array}$ & 0.67 & 0.75 & 0.86 & 0.80 & 0.86 \\
\hline $\begin{array}{c}\text { Multiplanar reconstruction } \\
\text { CBCT }\end{array}$ & 1.00 & 1.00 & 1.00 & 0.80 & 0.86 \\
\hline $\begin{array}{c}\text { i-CAT Vision } \\
\text { Sagittal/coronal slices }\end{array}$ & & & & \\
\hline
\end{tabular}

Table 6 - Percentages of agreements in relation to the gold standard in the examination of CBCT using the i-CAT Vision ${ }^{\circledR}$ software, comparing the evaluation of multiplanar reconstructions vs. sagittal/coronal slices, using the $z$ test.

\begin{tabular}{c|c|c|c|c|c}
\hline \multirow{2}{*}{$\begin{array}{c}\text { Size of simulated } \\
\text { lesion }\end{array}$} & \multicolumn{5}{|c}{ P values for the $\mathrm{z}$ test of comparisons of percentages } \\
\cline { 2 - 6 } & Anterior & Lateral & Posterior & Medial & Superior \\
\hline Absent & 0.211 & 0.450 & 0.983 & 0.999 & 0.999 \\
\hline Drill bit 1 & 0.974 & 0.270 & 0.991 & 0.999 & 0.991 \\
\hline Drill bit 3 & 0.999 & 0.604 & 0.992 & 0.999 & 0.207 \\
\hline Drill bit 6 & 0.999 & 0.974 & 0.999 & 0.966 & 0.999 \\
\hline
\end{tabular}

the protocols. Table 4 shows the sensitivity of each protocol used according to the region examined.

Table 5 shows the specificity of each protocol used according to the region examined by observer 1.

Table 6 presents the percentages of agreements in relation to the gold standard, analyzed using the $\mathrm{z}$ test, as a cross-check for the protocols used. In this way, it was possible to establish statistically the existence or not of differences between these protocols.

From the results of analyses shown in Table 6, it can be concluded that statistically there are no differences between the results of the evaluations of multiplanar reconstructions and the evaluations of sagittal/coronal slices in relation to the longitudinal axis of the mandibular condyle.

\section{Discussion}

Many studies have been performed about radiographic evaluation of the articular degenerative disease located in the temporomandibular joint. ${ }^{12,13}$

The radiographic patterns, which characterize the presence of degenerative diseases in the TMJ, show erosions of the mandibular condyle and reductions of articular biological space. The transcranial, transfacial, and panoramic radiographs are limited for this type of evaluation, due to the overlaps and distortions peculiar to these methods. ${ }^{2,9}$

Computed tomography has been used in the last decades, with satisfactory results, for the evaluation of bone alterations in the TMJ. Similar satisfactory results have been observed in the present work. ${ }^{3,14-16}$

More recently, cone beam computed tomography has been the object of study for TMJ evaluation by various authors who consider it the best recom- 
mended method for these cases. ${ }^{11,15,17,18}$

Gaia and Cavalcanti ${ }^{19}$ performed a study of the different CT protocols for bone affections of the temporomandibular joint, emphasizing that $\mathrm{CT}$ can be considered as the standard image for investigation of TMJ when using axial images and multiplanar reconstruction (MPR). In the present study, the visualization was improved by using sagittal and coronal slices along the longitudinal axis of the mandibular condyle, as they added information regarding some anatomical regions.

Similarly to the studies of Utumi et al. ${ }^{20}$ and Cara et al.,${ }^{14}$ the statistical methodology used in this study considered just one intra-observer analysis in order to avoid increasing costs and time, without losing the accuracy of the results, compared to the use of two intra-observer analyses. Additionally, a second observer was not considered because it would not increase sufficiently the number of observers to characterize a statistically representative sample.

The results of this study corroborate the research of Cara et al., ${ }^{14}$ in which they found a high level of sensitivity and specificity using multislice CT to identify mandible condyle lesions. Furthermore, our study demonstrated very similar sensitivity and specificity in both protocols when CBCT images were assessed.

Utumi et al. ${ }^{20}$ also found a high level of sensitivity and specificity using multislice CT with parasagittal reconstruction. The same was found, with sagittal and coronal slices along the axis of the mandibular condyle, in the present work.

Bone lesions were simulated in dry mandibular condyles, using three sizes of drill bits. This is the same methodology used in the work of Utumi et $a l^{20}$ This methodology was chosen in order to obtain a Gold Standard, which would permit an easy comparison of the results obtained by the observers, allowing for statistical treatment.

For the two protocols tested, the percentages of agreements (concordance) of hole presence identified by the observers were calculated in all the regions of the mandibular condyle, and in relation to the size of the hole. It was observed that the larger the size of the hole, the higher the percentages of agreements by the observers. The results are similar regarding the average size of holes, as well as the absence of any holes, irrespective of the protocol used. Concerning the smaller-size holes, the percentage of agreements in relation to the gold standard was lower. All observers concurred with this fact. Analyzing these results, it was noted that even in accurate exams with high resolution like computed tomography, the smaller the bone lesion, the more difficult its identification will be, according to Tsiklakis et al. ${ }^{10}$ and Hussain et al. ${ }^{6}$

Applying the $\mathrm{z}$ test, the results showed that the percentage of agreements between the observers did not differ very much, according to the protocols used. It was observed that no statistically significant differences were found $(\mathrm{P} \leq 0.05)$ in the intra-observer comparisons, demonstrating the reproducible feature of the technical protocols. Only the protocol of sagittal/coronal slices throughout the longitudinal axis of the mandibular condyle showed statistically significant differences in the inter-observer comparisons. In the other cases, no statistically significant differences were noted.

Ludlow et al. ${ }^{8}$ performed a comparative study in vitro of the degree of accuracy for the detection of bone alterations in the TMJ region with the CT multislice, using sagittal and coronal images (multiplanar reconstructions) and panoramic radiographs. The multiplanar reconstructions showed greater accuracy for the evaluation of bone lesions in the mandibular condyle than the panoramic images. In comparison to their study, the present work has demonstrated differences in the percentage of agreements concerning the position of the simulated lesions in the mandibular condyle, related to the diameter of the drill bits. Concerning the concordance, in each analyzed region, it was observed that the images did not present significant differences.

\section{Conclusions}

- Cone beam computed tomography was validated for the assessment of the presence or absence of bone lesions, even for small ones, confirming the results of studies already published in the litera- 
ture.

- Both post-processing protocols of CBCT were considered to be adequate in the assessment of bone lesions in the mandibular condyle, with the multiplanar reconstruction protocol showing slightly better results.

\section{References}

1. Saeed NR, McLeod NM, Hensher R. Temporomandibular joint replacement in rheumatoid - induced disease. Br J Oral Maxillofac Surg. 2001 Feb;39(1):71-5.

2. Akerman S, Jonsson K, Kopp S, Petersson A, Rohlin M. Radiologic changes in temporomandibular, hand, and foot joints of patients with rheumatoid arthritis. Oral Surg Oral Med Oral Pathol. 1991 Aug; 72(2):245-50.

3. Perrella A, Borsatti MA, Tortamano IP, Rocha RG, Cavalcanti MG. Validation of computed tomography protocols for simulated mandibular lesions: a comparison study. Braz Oral Res. 2007 Apr-Jun;21(2):165-9.

4. Cavalcanti MG, Ruprecht A, Bonomie JM, Vannier MW. Accuracy and precision of spiral CT in the assessment of neoplastic lesions associated with the mandible. Acad Radiol. 2000 Feb;7(2):94-9.

5. Sales MA, Oliveira JX, Cavalcanti MG. Computed tomography imaging findings of simultaneous bifid mandibular condyle and temporomandibular joint ankylosis: case report. Braz Dent J. 2007;18(1):74-7.

6. Hussain AM, Packota G, Major PW, Flores-Mir C. Role of different imaging modalities in assessment of temporomandibular joint erosions and osteophytes: a systematic review. Dentomaxillofac Radiol. 2008 Feb;37(2):63-71.

7. Larheim TA, Bjornland T, Smith HJ, Aspestrand F, Kolbenstvedt A. Imaging temporomandibular joint abnormalities in patients with rheumatic disease. Comparison with surgical observation. Oral Surg Oral Med Oral Pathol. 1992 Apr;73(4):494-501.

8. Ludlow JB, Davies KL, Tyndall DA. Temporomandibular joint imaging: a comparative study of diagnostic accuracy for the detection of bone change with biplanar multidirectional tomography and panoramic images. Oral Surg Oral Med Oral Pathol Oral Radiol Endod. 1995 Dec;80(6):735-43.

9. Marques AP, Moraes LC. Prevalência de alterações da articulação temporomandibular por meio de exames de tomografia computadorizada. Rev Bras Odont. 2006;63(3,4):198-201.

10. Tsiklakis K, Syriopoulos K, Stamatakis HC. Radiographic examination of the temporomandibular joint using cone

\section{Acknowledgements}

To CNPq, Brasilia, Brazil, Dr. Marcelo Cavalcanti (Universal Project - grants \#484848/20062 and Research Productivity Scholarship - grants \#306509/2006-7).

beam computed tomography. Dentomaxillofac Radiol. 2004 May;33(3):196-201.

11. Winter AA, Pollack AS, Frommer HH, Koenig L. Cone beam volumetric tomography vs. medical CT scanners. N Y State Dent J. 2005 Jun-Jul; 71(4):28-33.

12. Tsuruta A, Yamada K, Hanada K, Hosogai A, Tanaka R, Koyama J, et al. Thickness of the roof of the glenoid fossa and condylar bone change: a CT study. Dentomaxillofac Radiol. 2003 Jul;32(4):217-21.

13. Yamada K, Tsuruta,A, Hanada K, Hayashi,T. Morphology of the articular eminence in temporomandibular joints and condylar bone change. J Oral Rehabil. 2004 May;31(5):43844.

14. Cara AC, Gaia BF, Perrella A, Oliveira JX, Lopes PM, Cavalcanti MG. Validity of single- and multislice CT for assessment of mandibular condyle lesions. Dentomaxillofac Radiol. 2007 Jan;36(1):24-7.

15. Cavalcanti MGP. Tomografia computadorizada por feixe cônico. Interpretação e diagnóstico para o cirurgião-dentista. 1a ed. São Paulo: Ed. Santos; 2009. 244 p.

16. Hintze H, Wiese M, Wenzel A. Cone beam CT and conventional tomography for the detection of morphological temporomandibular joint changes. Dentomaxillofac Radiol. 2007 May;36(4):192-7.

17. Mozzo P, Procacci C, Tacconi A, Martini PT, Andreis IA. A new volumetric CT machine for dental imaging based on the cone-beam technique: preliminary results. Eur Radiol. 1998;8(9):1558-64.

18. Pinsky HM, Dyda S, Pinsky RW, Misch KA, Sarment DP. Accuracy of three dimensional measurements using cone-beam CT. Dentomaxillofac Radiol. 2006 Nov;35(6):410-6.

19. Gaia BF, Cavalcanti MGP. Afecções ósseas da articulação temporomandibular: protocolos em tomografia computadorizada. Rev Assoc Paul Cir Dent. 2005 Jul-Aug;59(4):297-302.

20. Utumi ER, Perrella A, Albuquerque MA, Adde CA, Rocha RG, Cavalcanti MGP. Evaluation of simulated bone lesion in the head of the mandible by using multislice computed tomography. J Appl Oral Sci. 2009 Sep-Oct;17(5):521-6. 